\title{
Selected Abstracts of the 2nd International Iranian Ergonomics Conference and the 2nd Biennial Iranian Conference on Ergonomics
}

\author{
Velayat Complex, Shiraz, Iran \\ October 19-21, 2016
}

\author{
Shiraz Electronic Medical Journal \\ Supplement 1 \\ December 2016
}

doi: 10.17795/semj45591

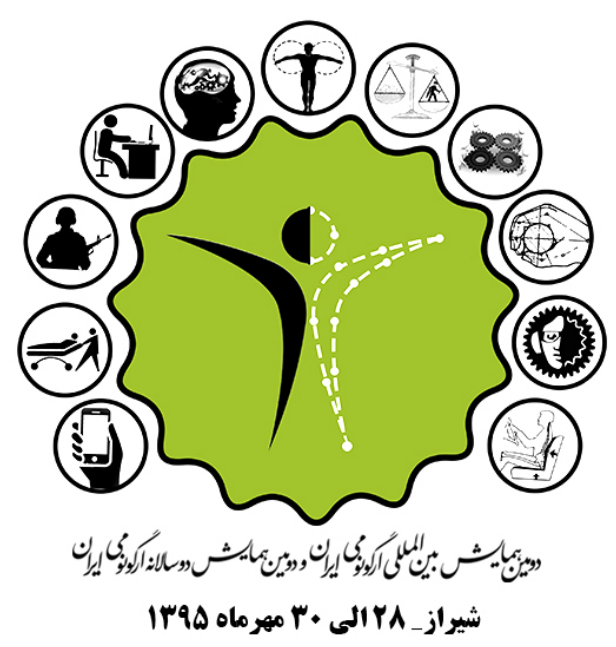

Research Center for Health Sciences, Institute of Health, Shiraz University of Medical Sciences, Shiraz, Iran
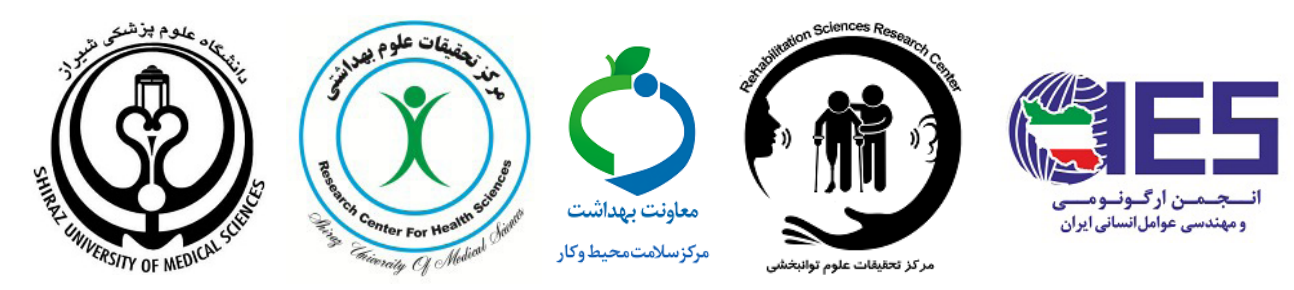



\section{"Ergonomics, entrepreneurship, moving towards}

the third generation of universities"

\section{Hosted by}
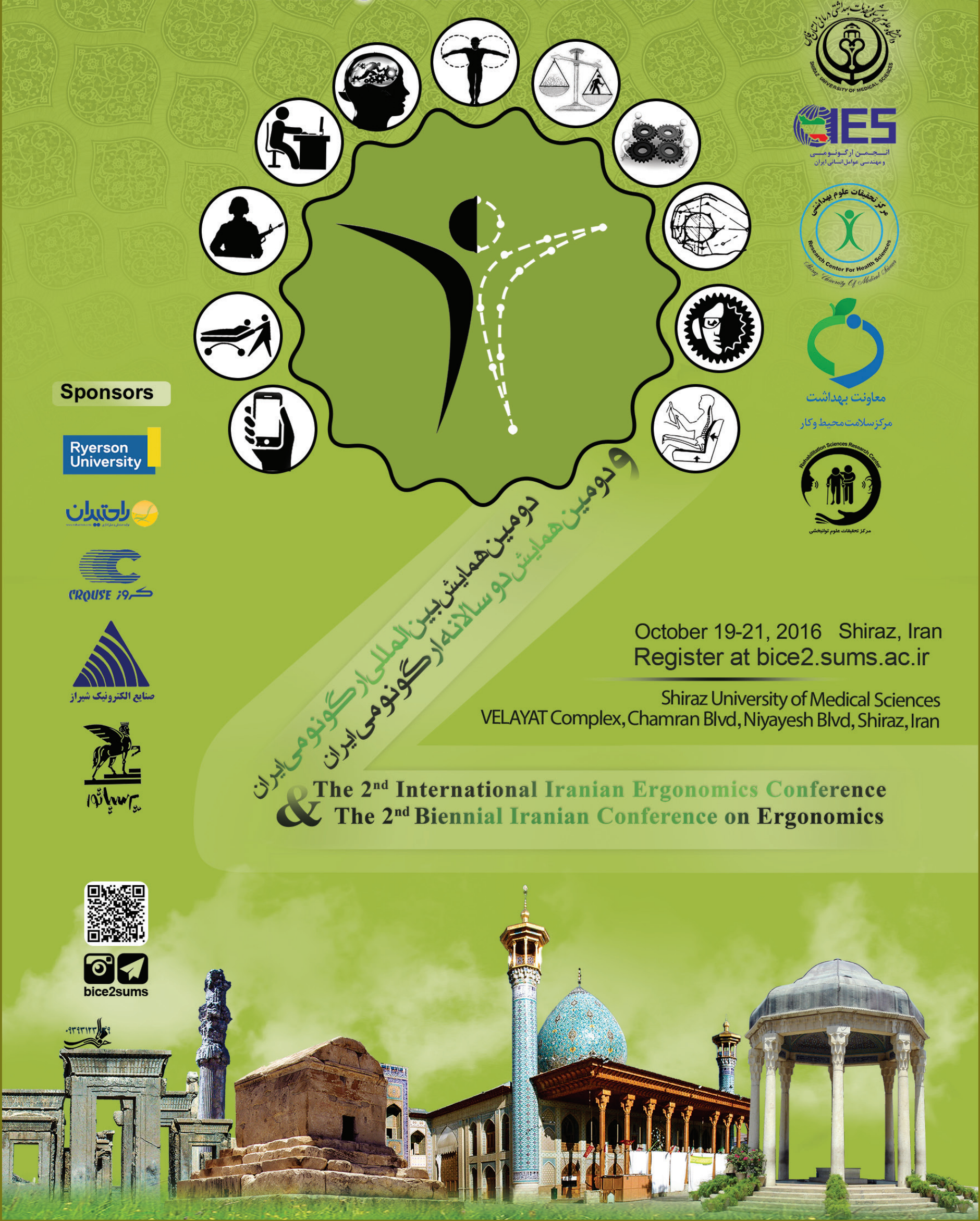



\section{Contents}

\section{December, 2016}

Introduction

\section{Abstracts}

1. Ergonomics Intervention for Stress Reduction: A Case Study in a Cement Company...

2. Designing an Ergonomic Surgeon's Seat

3. An Ergonomic Intervention Using a Device for Improving Shoulders Posture and Reducing Musculoskeletal Symptoms Among

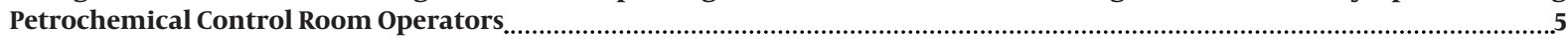

4. The Relationship Between Workplace Social Capital and Mental Health in Workers .......................................................................6

5. The Effect of Back School Guidelines on Pain and Disability in Employees With Chronic Non-Specific Neck Pain ..........................6

6. Designing and Modeling a Half-Face Mask Respirator Based on Anthropometrics of Iranian Workers .........................................6

7. Investigating the Relationship Between Absolute Beta Power and Mental Fatigue Self-Assessment on a Driving Simulator........7

8. Cognitive Features Hierarchical Analysis of 6 Dynamic Symbols in Designing a Technology of Warning Lane Departure to Other Drivers.

9. Movement Variability and Coordination in Healthy and NLBP Participants During Repetitive Trunk Bending: The Effect of

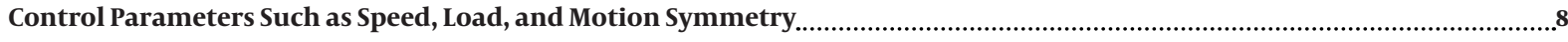

10. Cultural Ergonomics and Its Application in Creating Inclusive Warnings ........................................................................................8

11. The Impact of Ergonomic Interventions on the General Health Conditions of Employees of Iran Khodro Company (IKCO)........9

12. The Relationship Between Job Stress and Smoking Among the Employees of a Petrochemical Industry Based on the Job Demands and Control Model.

13. Identifying Factors Affecting the Return-to-Work of National Iranian Oil Company Administrative Staff with a History of Low

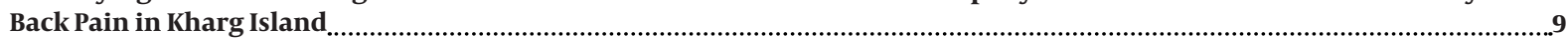

14. Investigating Mental Workload in Air Traffic Control Using Electroencephalography (EEG) Signals ...........................................10

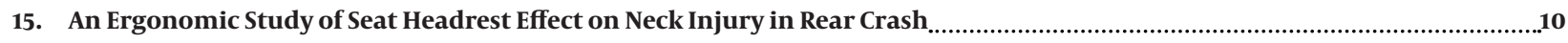

16. Human Errors Assessment in the Control Room of Drilling Rig at MAPNA Company Using SHERPA Method ...............................11

17. Ergonomic Intervention Based on the Results of MAC and ART Evaluation Methods at Nestle Iran Company...............................11

18. Ergonomically Adjustable Laptop Desk Designed Based on Anthropometric Data of Students of Mazandaran University of

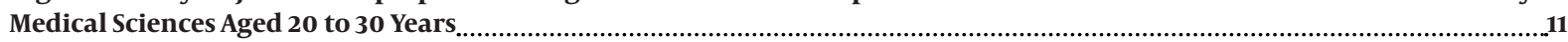

19. Surveying the Relationship Between Organizational Support and Physical Environment Conditions with Burnout of

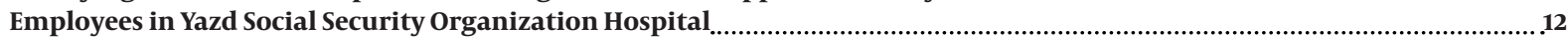

20. The Relationship Between Lighting and Visual Eye Fatigue and Sleep Quality in Video Display Terminal (VDT) Users................12

21. Measuring Anaerobic Power and Speed of Muscle Contraction: Criterion for Selecting Medical Emergencies Students ...............12

22. A Survey on Ergonomics Research Trend in Iran Based on Papers Published in Scientific Persian Language Journals During 2013

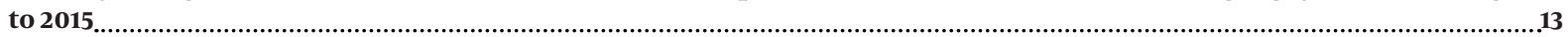

23. The Effects of Light Color Temperature on Circadian Rhythm, Sleepiness, and Cognitive Functions of Night Shift Workers.......13

24. Housekeeping or Employment: From the Perspective of Musculoskeletal Pain ..........................................................................14

25. Ergonomics Modification to Prevent Musculoskeletal Injuries in the Personnel of Iran Khodro Warehouse ..............................14

26. Designing a New Table Based on Iranian Anthropometric Data and Evaluating Its Effects on the Users Posture While Working

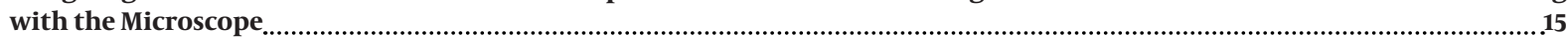

27. Evaluation of Cardiorespiratory Fitness and Some Related Factors in the Fire-Fighting Personnel ..........................................15

28. The Effects of Shoe Insoles on Lower Leg Muscle Activity and Volume Changes During Prolonged Standing ..............................16

29. Investigating Muscle Fatigue Trend in the Clutch Pedal Actuation of Four Automobile Models in Iran's Market........................16

30. Index 



\section{In the Name of the Most High}

"The 2nd International Iranian Ergonomics Conference and the 2nd Biennial Iranian Conference on Ergonomics" was held from 19 to 21 October 2016 at Shiraz University of Medical Sciences (SUMS), Shiraz, Iran. The conference brought together over 570 professionals from 3 countries including Iran, Canada, and Sweden to share their experiences in diverse areas of Ergonomics. The conference theme was "Ergonomics, entrepreneurship, moving towards the third generation of universities" and was hosted by SUMS together with the Iranian Ergonomics and Human Factors Engineering Society (IES).

In this event, there were 43 oral and 151 poster presentations from academic and industrial sectors. Additionally, 9 keynote talks were given by internal and external experts. Two scientific panels with the topics of (a) "scopes of education and research in ergonomics and employment of graduated students in Iran", and (b) "ergonomics in industry: opportunities and challenges" were also implemented during the event.

Furthermore, 13 applied workshops in different aspects of ergonomics including physical demand analysis, posture assessment, biomechanics, EEG signal processing, DHM, motion analysis, EMG, and electro-goniometry were held and attended by more than 300 participants.
Some highlights and notable achievements of the conference were as follow:

(1) The scientific quality of the papers and speeches was very high and comparable with international standards.

(2) An interdisciplinary group of professionals working in the field of ergonomics was brought together.

(3) Many different investigators from diverse departments including rehabilitation, industrial engineering, occupational health, and ergonomics presented in the conference.

(4) Some industries and companies attended the conference with relevant products to support the event.

(5) To achieve a more efficient performance, students were actively involved in supporting the leaders and the executive committee.

\section{Professor Alireza Choobineh, PhD \\ Scientific secretary of the conference \\ Research Center for Health Sciences, Institute of Health \\ Shiraz University of Medical Sciences.}

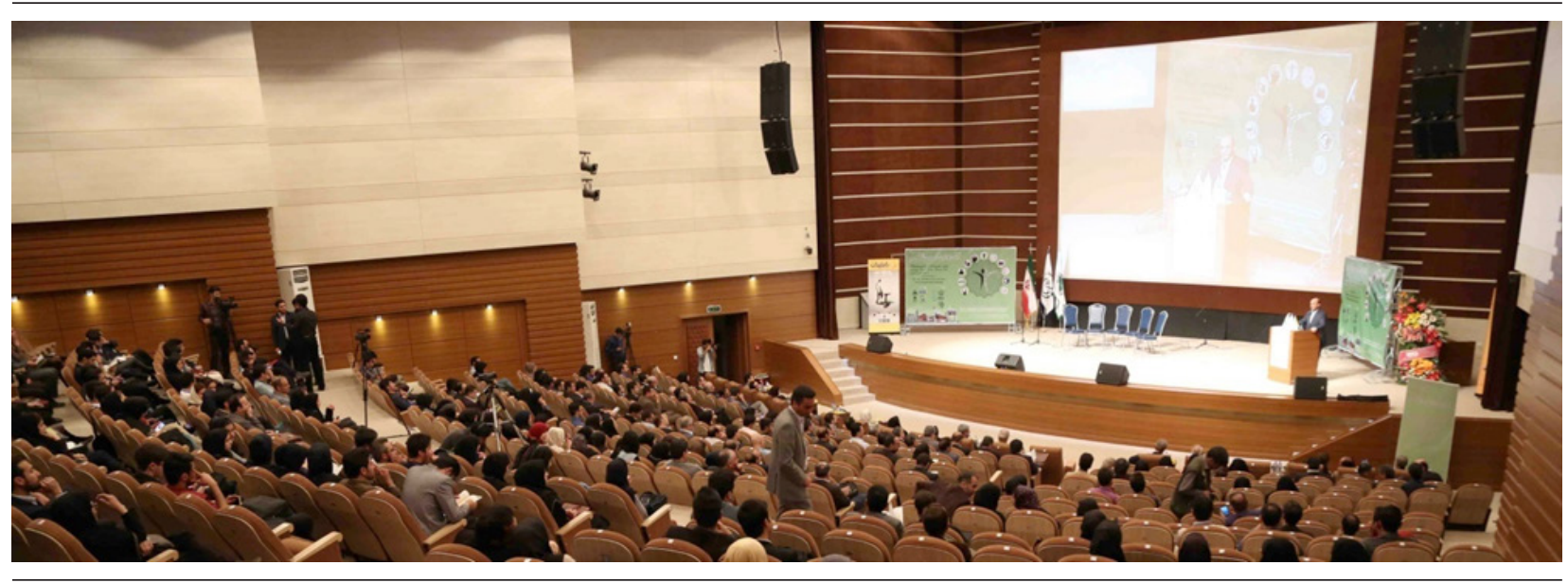

Opening Ceremony, Shiraz University Hall, Shiraz, October 18th, 2016 


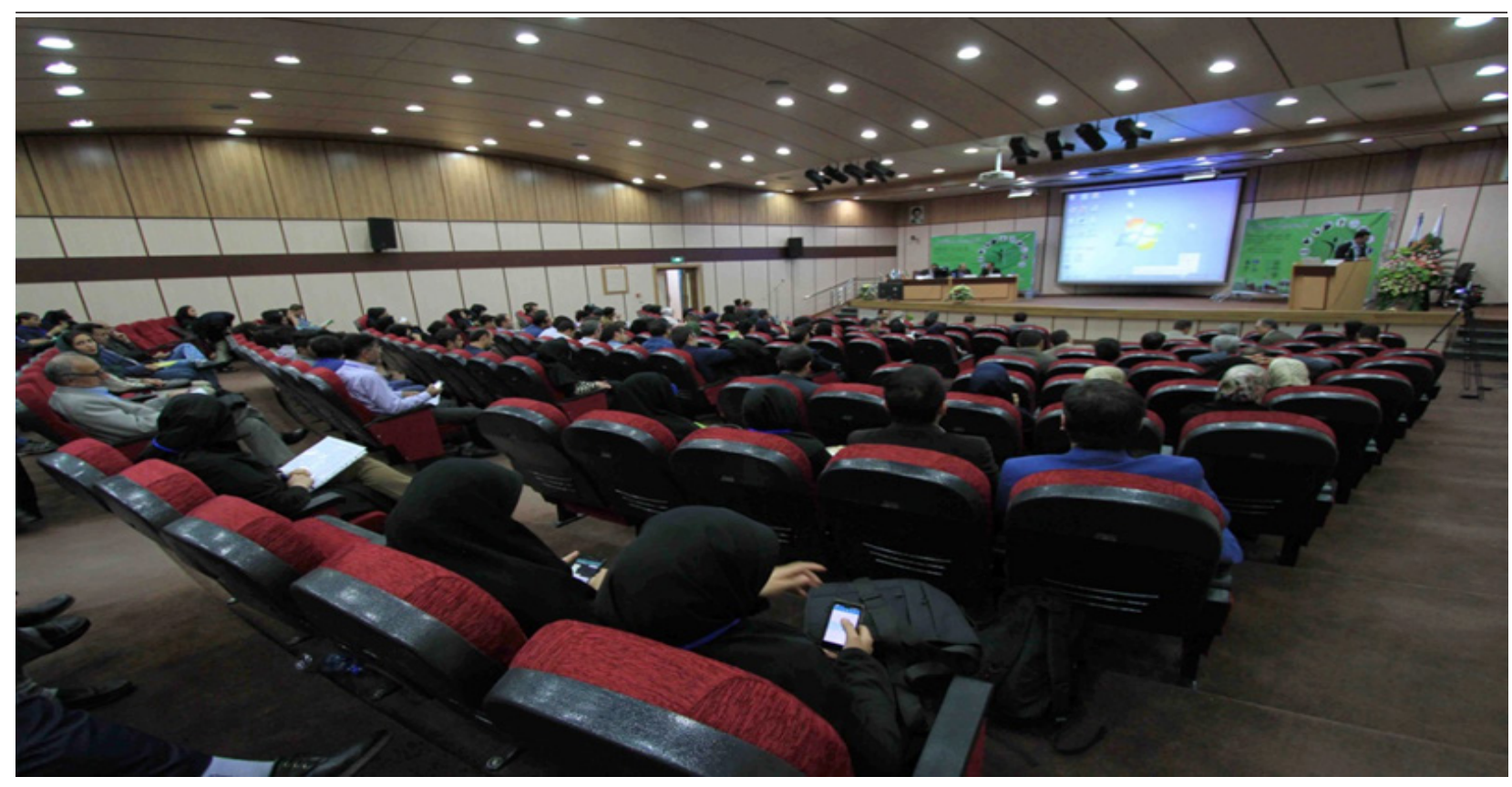

Oral Presentation, Sa'adi Hall, SUMS, Shiraz, October 19th, 2016

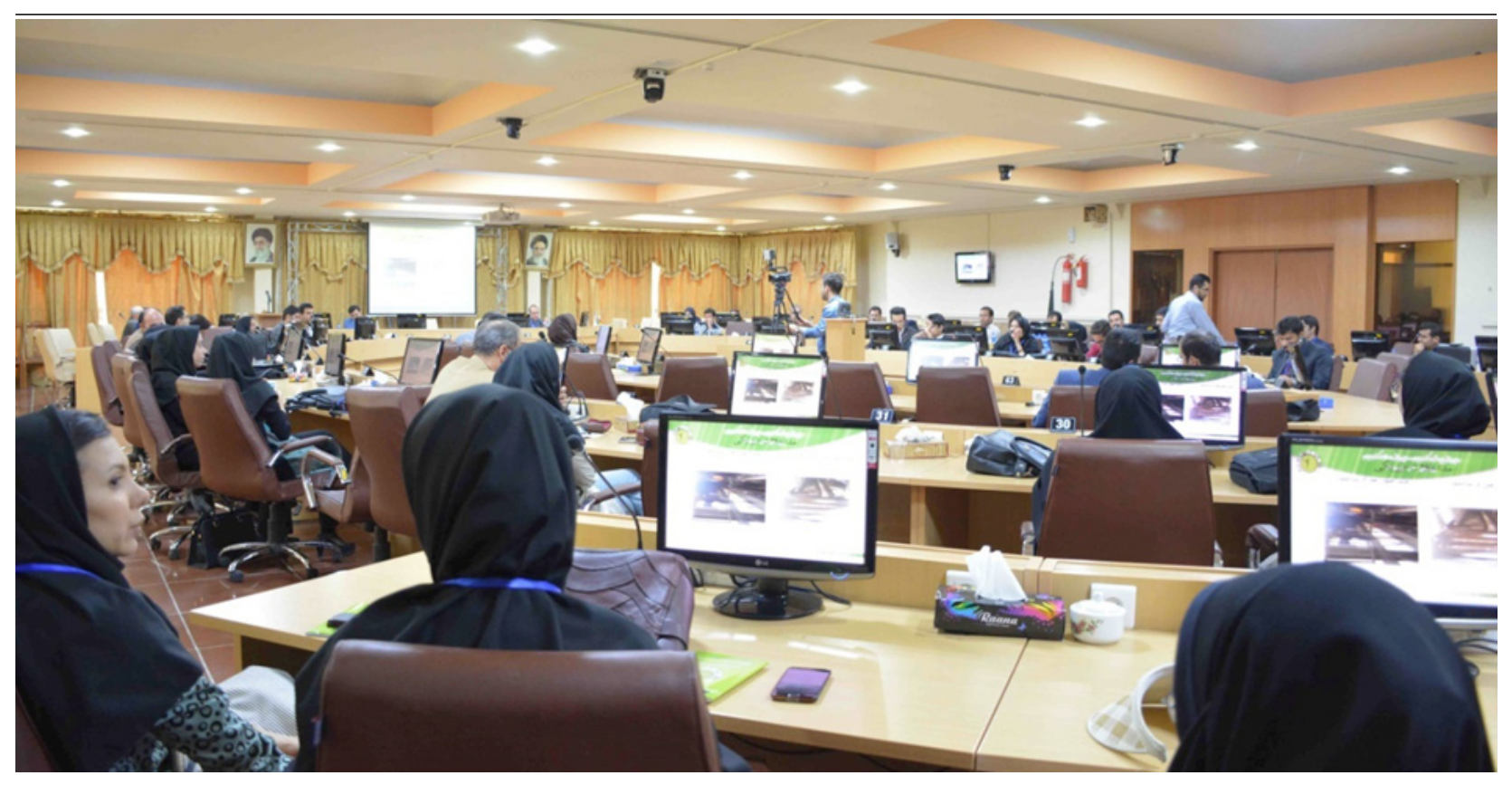

Oral Presentation, Aborayhan Hall, SUMS, Shiraz, October 20th, 2016 


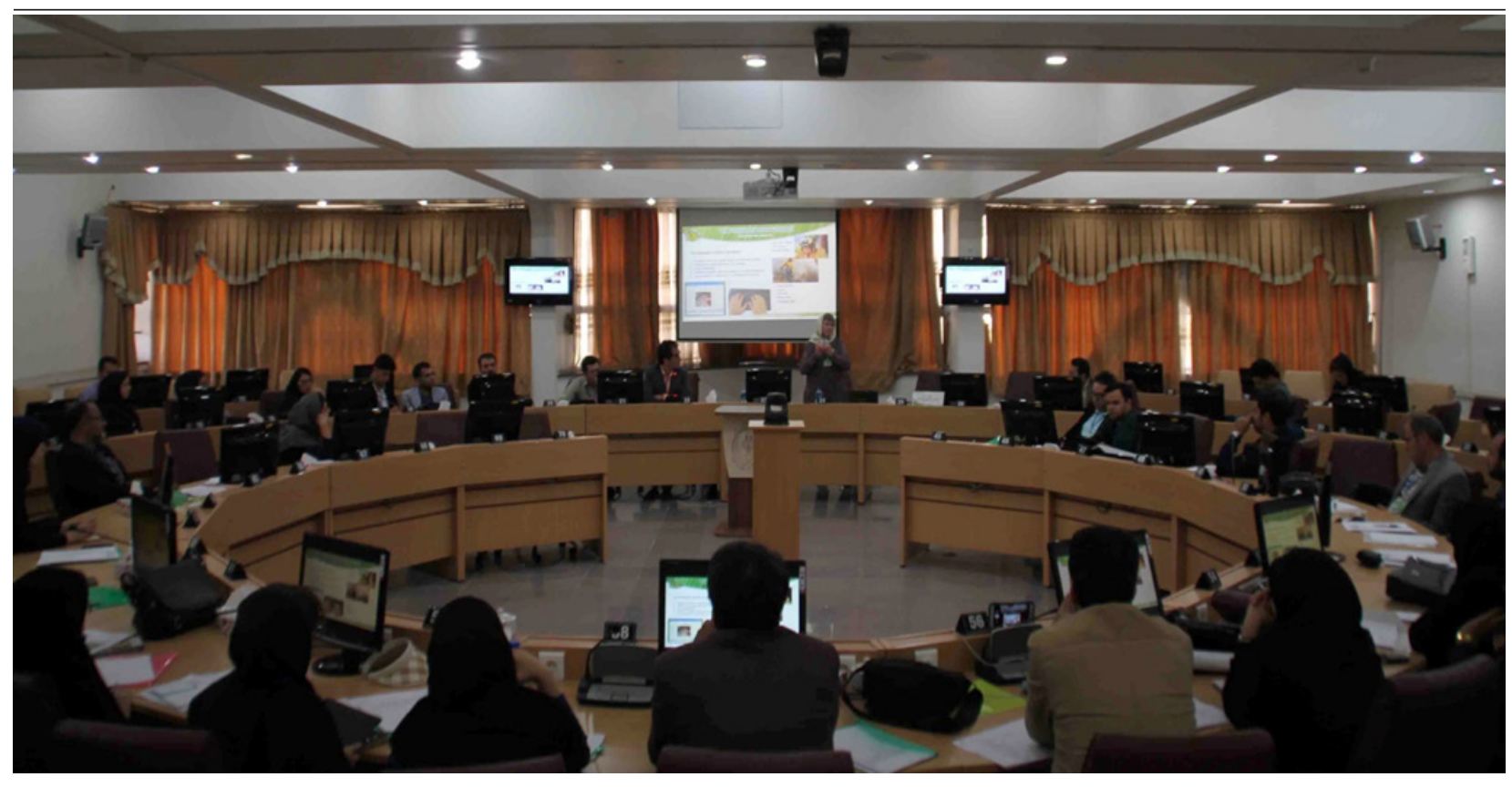

Workshop on "Physical Demands Analysis and Employee Selection: Strategies to Consider to Reduce Injuries in Manual Handling Jobs" by Professor Stevenson, Razi Hall, SUMS, Shiraz, October 20th, 2016 



\section{-Ergonomics Intervention for Stress Reduction: A Case Study in a Cement Company}

Majid Motamedzadeh ${ }^{1}$, Rashid Haydarimoghadam ${ }^{1}$, Javad Faradmal ${ }^{2}$, Abbas Moradi ${ }^{3,}$

${ }^{1}$ Department of Ergonomics, School of Public Health and Research Center for Health Sciences, Hamadan University of Medical Sciences, Hamadan, IR Iran

${ }^{2}$ Modeling of Non Communicable Diseases Research Center \& Department of Biostatistics, School of Public Health, Hamadan University of Medical Sciences, Hamadan, IR Iran

${ }^{3}$ MSc. Student of Ergonomics, School of Public Health and Research Center for Health Sciences, Hamadan University of Medical Sciences, Hamadan, IR Iran

* Corresponding author: Abbas Moradi, MSc. Student of Ergonomics, School of Public Health and Research Center for Health Sciences, Hamadan University of Medical Sciences, Hamadan, IR Iran. E-mail: moradiabbas92@gmail.com

\begin{abstract}
Background: Stress can develop some physical, psychological, and social illnesses and increase accidents. Improving safety, health, and work conditions affect physical and mental health. objectives: This study aimed at implementing ergonomics solutions to reduce work- related stress in a cement company. Method: This interventional study was conducted on 126 preservation and maintenance workers in a cement company using classification sampling. The QEC method and ergonomics checkpoints were used to collect data before and after the intervention. Data were analyzed by Mcnemar test using SPSS Version 22. Results: Data analysis revealed a significant difference (P value < 0.001 ) in prevalence of stress before and after the interventions. Prevalence of a very stressful state of mind was $42.86 \%$ before the intervention, but it was reduced to $23.81 \%$ after the intervention. Conclusions: According to QEC method, 83 maintenance workers (65.87\%) were at high risk, and prevalence of stress was high. Implementing simple, inexpensive, and participatory solutions of ergonomics checkpoints lead to stress reduction.

Keywords: Stress, Participatory, Ergonomics Intervention
\end{abstract}

\section{-Designing an Ergonomic Surgeon's Seat}

Adibeh Abdi ${ }^{1}$, Alireza Choobineh ${ }^{2,}$, Mohsen Razeghi $^{3}$, Ali Ghanbari ${ }^{3}$, Abdolkarim Rahmanian ${ }^{4}$, Mohamad Ghorbani ${ }^{5}$

${ }^{1}$ Department of Ergonomics, School of Health, Shiraz University of Medical Sciences, Shiraz, IR Iran

2 Research Center for Health Sciences, Institute of Health, Shiraz University of Medical Sciences, Shiraz, IR Iran

${ }^{3}$ Department of Physiotherapy, School of Rehabilitation Sciences, Shiraz University of Medical Sciences, Shiraz, IR Iran

${ }^{4}$ Department of Neurosurgery, School of Medicine, Shiraz University of Medical Sciences, Shiraz, IR Iran

${ }^{5}$ Department of Epidemiology, School of Health, Shiraz University of Medical Sciences, Shiraz, IR Iran

* Corresponding author: Alireza Choobineh, Research Center for Health Sciences, Institute of Health, Shiraz University of Medical Sciences, Shiraz, IR Iran. Tel: +98-7137251020, Fax:+98-7137250053, E-mail:alrchoobin@sums.ac.ir

\section{Abstract}

Background: Awkward postures and prolonged standing are important risk factors for musculoskeletal injuries among surgeons. While performing surgical operations, the surgeons cannot sit on typical seats and adapt appropriate postures.

Objectives: The present study aimed at designing a new ergonomic seat to be used by the surgeons at the operating room. Methods: In the present study, a special surgery seat was designed using ergonomic principles; and its prototype was made. Ergonomic evaluations on the functional parameters of the prototype were carried out on 8 surgeons in real conditions in the operating room using the subjective method. Subjective assessments were performed using visual analogue scales (VAS) and body map. Statistical analyses were conducted using SPSS Version 22.

Results: The newly designed saddle seat with its knee support and appropriate footrest allowed more proper and comfortable working postures in surgeons. Surgeons' comfort was improved while using the seat in surgical operations compared to performing operations in the standing position. The difference was statistically significant $(\mathrm{P}<0.001)$.

Conclusions: Based on the results, it could be concluded that the newly designed surgery seat with its specific features improved surgeons' comfort and working postures during the operations. Accordingly, using the seat during the surgical operations could prevent musculoskeletal pain and injuries among the surgeons. Keywords: Seat, Ergonomic Design, Surgery

\section{-An Ergonomic Intervention Using a Device for Improving Shoulders Posture and Reducing Musculoskeletal Symptoms Among Petrochemical Control Room Operators}

\author{
Ahmad Bazazan 1,, Nafiseh Feizollahi ${ }^{2}$, Zohreh \\ Mombeini ${ }^{3}$, Alireza Mohammad Shirazi ${ }^{4}$ \\ ${ }^{1}$ Department of Ergonomics, Faculty of Health, Tabriz University of Medical Sciences, \\ Tabriz, IR Iran \\ ${ }^{2}$ M.Sc. of Power Electronics, Islamic Azad University, South Tehran, IR Iran \\ ${ }^{3}$ Department of Health Safety and Environment (HSE), Razi Petrochemical Company, \\ Mahshahr, IR Iran \\ ${ }^{4}$ M.Sc. of Business Administration, Islamic Azad University, Science and Research, IR \\ Iran
}

${ }^{*}$ Corresponding author: Ahmad Bazazan, Department of Ergonomics, Faculty of Health, Tabriz University of Medical Sciences, Tabriz, IR Iran. Tel: +98-9368668873, E-mail: bazazan_a@yahoo.com

\section{Abstract}

Background: Due to prolonged sitting, high mental workload, and shift work, the control room operators are exposed to several risk factors including musculoskeletal disorders (MSDs). Prevention of MSDs is, therefore, one of the most important factors influencing the productivity enhancement and promoting health and safety at work.

Objectives: The present study aimed at examining the effects of ergonomic intervention on musculoskeletal symptoms among the control room operators of an Iranian petrochemical plant. Methods: This was a prospective, randomized controlled 6-month intervention study. The intervention was using a device to improve shoulders posture, which works based on a simple biofeedback principle. The Nordic Musculoskeletal Disorders Questionnaire and demographic factors were used for data collection before and after the interventional program. In the pre- 
sent study, from among the control room operators, 91 operators were randomly selected and examined as case and 97 operators as control groups.

Results: The average age and work experience of the participants were 33 and 6 years, respectively. After a 6-month intervention period, a reduction in prevalence rates of musculoskeletal symptoms was found in the neck $(P=0.004)$, shoulders $(\mathrm{P}<0.001)$, upper back $(\mathrm{P}=0.002)$, and lower back $(\mathrm{P}=0.016)$ regions. Moreover, a high prevalence of musculoskeletal symptoms, particularly, in the shoulders, upper back, and neck was reported. However, no significant difference was found in the control group $(\mathrm{P}>0.05)$.

Conclusions: The results of the current study highlighted that a well-conducted implementation of an interventional program could decrease musculoskeletal problems. Taken together, our findings can help improve the performance and productivity in control room operators, eventually declining the rate of accidents and costs in this petrochemical plant.

Keywords: Musculoskeletal Pain, Occupational Injuries, Human Factors and Ergonomics

\section{-The Relationship Between Workplace Social Capital and Mental Health in Workers}

\author{
Mojgan Firouzbakht ${ }^{1}$, Maryam Nikpour ${ }^{1}$, Reza \\ Sadeghian ${ }^{2}$, Aram Tirgar ${ }^{1, *}$ \\ ${ }^{1}$ Social Determinants of Health Research Center, Health Research Institute, Babol Uni- \\ versity of Medical Sciences, Babol, Iran \\ ${ }^{2}$ Student of Occupational Health Enginering, Semnan University of Medical Sciences, \\ Semnan, IR Iran
}

${ }^{*}$ Corresponding author: Aram Tirgar, Social Determinants of Health Research Center, Health Research Institute, Babol University of Medical Sciences, Babol, IR Iran. Tel: +981132190560, E-mail:a.tirgar@mubabol.ac.ir

\footnotetext{
Abstract

Background: Mental health is an important aspect of health and a main factor for determining the success and progress of industrial organizations. Social capital is an important factor influencing mental health. The present study aimed at examining the relationship between workplace social capital and mental health of industrial workers in Babol, Iran.

Methods: In this cross-sectional study, 150 workers were selected by simple sampling method. Data collection tools were demographic, GHQ-12, and workplace social capital questionnaires. Data were analyzed using descriptive statistics and regression analysis.

Results: The means of mental health score (GHQ-12) and workplace social capital were found to be $2.86 \pm 2.49$ and $29.65 \pm 7.56$ respectively. Around $47 \%$ of the participants had high workplace social capital, and $77.2 \%$ had good mental health. A significant positive relationship was found between workplace social capital and mental health $(\mathrm{P}=0.01)$.

Conclusions: The present study revealed that social capital is an effective factor in maintaining employees' mental health at the workplace. Therefore, promoting workplaces' social capital to improve mental health of the workers is highly recommended.

Keywords: Workplace Social Capital, Mental Health, Industrial, Workers
}

\section{-The Effect of Back School Guidelines on Pain and Disability in Employees With Chronic Non-Specific Neck Pain}

\author{
Ehsan Sinaei ${ }^{1, *}$, Fahimeh Kamali ${ }^{2}$ \\ ${ }^{1}$ Student Research Committee, School of Rehabilitation Sciences, Shiraz University of \\ Medical Sciences, Shiraz, IR Iran \\ ${ }^{2}$ Center for Human Motion Science Research, Department of Physiotherapy, School o \\ Rehabilitation Sciences, Shiraz University of Medical Sciences, Shiraz, IR Iran \\ Corresponding author: Ehsan Sinaei, School of Rehabilitation Sciences, Shiraz Unt- \\ versity of Medical Sciences, Shiraz, IR Iran. Tel: +98-9334887673, E-mail: ehsansinaie@ \\ yahoo.com
}

\begin{abstract}
Background: Chronic neck pain is one of the most prevalent musculoskeletal disorders among office staff, which is mainly due to improper postures and lack of regular physical activities. "Back School" is one of the most popular treatments in which the standard and optimal physical postures and exercises are instructed to individuals. Previous studies have examined this procedure mainly on low back pain. Hence, the present study aimed at evaluating the effects of back school training program on pain intensity and neck disability in employees who suffered chronic mechanical neck pain.
\end{abstract}

Methods: Seventy-two office employees with chronic nonspecific neck pain (aged 25 - 50 years) were allocated randomly into 2 groups of intervention and control. Pain intensity and functional disability levels were evaluated using numerical rating scale (NRS) and Neck disability index (NDI), respectively. A well-educated physiotherapist instructed the guidelines to the intervention group in a 1-hour session by means of an animation video. The intervention group participants were monitored over 3 months of the study to ensure that they observe the back school instructions. The control group examinees were followed without any specific treatment through the trial. After the 12th week, outcome measures were re-assessed for analysis.

Results: After 12 weeks of following the guidelines, both pain intensity and neck disability were decreased significantly in the intervention group $(\mathrm{P}<0.001)$, but no statically significant changes were observed in the control group.

Conclusions: Three months of observing instructed guidelines of proper postures during different activities could effectively relieve neck pain and disability in the staffers.

Keywords: Back School, Neck Pain, Disability, Posture

\section{-Designing and Modeling a Half- Face Mask Respirator Based on Anthropometrics of Iranian Workers}

\footnotetext{
Elham Salvarzi ${ }^{1}$, Alireza Choobineh ${ }^{2, *}$, Mehdi Jahangiri ${ }^{3}$, Sareh Keshavarzi ${ }^{4}$

${ }^{1}$ Ergonomics Department, School of Health, Shiraz University of Medical Sciences, Shiraz, IR Iran

2 Research Center for Health Sciences, Institute of Health, Shiraz University of Medical Sciences, Shiraz, IR Iran

${ }^{3}$ Occupational Health Engineering Department, School of Health, Shiraz University of Medical Sciences, Shiraz, IR Iran

${ }^{4}$ Epidemiology Department, School of Health, Shiraz University of Medical Sciences, Shiraz, IR Iran

*Corresponding author: Alireza Choobineh, Research Center for Health Sciences, Institute of Health, Shiraz University of Medical Sciences, Shiraz, IR Iran. Tel: +98-7137251020 Fax:+98-7137250053, E-mail: alrchoobin@sums.ac.ir
} 


\begin{abstract}
Background: One of the most important respiratory protective equipment that protects users against air-borne contaminants is a respirator. To be effective, respirators need to be in proportion to the size and shape of the users' faces. A big challenge in designing personal protective equipment is its optimal fit to the target population. Half-face mask respirators used in Iran are all imported, or produced by reverse engineering method, so are not in accordance with the users' facial dimensions.

Objectives: The present study aimed at determining the facial anthropometric dimensions of Iranian male workers, which is necessary for designing and modeling half-face mask respirators for Iranian workers.

Methods: This study was conducted in 2 phases. In the first phase anthropometric data bank of 10 facial dimensions were established for 50 male workers using photography method and Digimizer software. Dimensions were categorized in 3 sizes including small, medium, and large by the Mahalanobis distance. The second phase consisted of 2 steps including three-dimensional (3D) facial scanning, and modeling. Finally, half-face mask modeling was done using Autodesk, Maya, Z-Brush and Catia software.

Results: The means of age (years), weight $(\mathrm{kg})$, and height $(\mathrm{cm})$ of the participants were $34.1 \pm 11.4,78.9 \pm 20.8$ and $172.5 \pm 25.8$, respectively. The 25 th, 50 th, and 75 th percentiles were selected for small, medium, and large sizes. Finally, a three-dimensional modeling of a medium-size half-face mask respirator was produced.

Conclusions: The half-face mask respirator that was designed and modeled based on the facial dimensions of Iranian workers is appropriate and fit for the target population.
\end{abstract}

Keywords: Anthropometry, Design, Half-Mask Respirator, Modeling

\section{-Investigating the Relationship Between Absolute Beta Power and Mental Fatigue Self-Assessment on a Driving Simulator}

Faramarz Gharagozlou 1,*, Adel Mazloumi 2, Gebraeil Nasl Saraji ${ }^{2}$, Ali Motie Nasrabadi ${ }^{3}$, Ali Nahvi ${ }^{4}$, Mohammadreza Ashouri ${ }^{4}$, Hamed Mozaffari $^{4}$

${ }^{1}$ Department of Occupational Health Engineering, Kermanshah University of Medical Sciences, Kermanshah, IR Iran

2 Department of Occupational Health Engineering, Tehran University of Medical Sciences, Tehran, IR Iran

${ }^{3}$ Biomedical Engineering Department, Shahed University, Tehran, IR Iran

${ }^{4}$ Department of Mechanical Engineering, Khaje Nasir Toosi University of Technology, Tehran, IR Iran

* Corresponding author: Faramarz Gharagozlou, Department of Occupational Health Engineering, Research Center for Environmental Determinants of Health (RCEDH), Kermanshah University of Medical Sciences, Kermanshah, IR Iran. Tel:+98-8338262005, Fax:+98-8338263048, E-mail: gharagozlouf@yahoo.com

\footnotetext{
Abstract

Background: Using EEG to detect driver fatigue is very challenging, and yet no reliable method has been provided for detecting
}

fatigue in drivers. Therefore, this study aimed at investigating the relationship between absolute beta and mental fatigue selfassessment on a driving simulator.

Methods: This cross-sectional study was conducted on 30 healthy intercity bus drivers. The drivers were asked to operate a driving simulator on a $107 \mathrm{~km}$ virtual monotonous road at a constant speed of 110 kilometers per hour. With the onset of the experiment, the drivers' fatigue levels were evaluated using fatigue-visual analog scale (F-VAS) in every 10 minute interval. At the same time, EEG data were recorded from different areas of the brain. After the filtering and artefact removal of EEG signals, the frequency bands of Beta were obtained using fast Fourier transform. Spearman correlation test was used to examine the association between beta absolute power and mental fatigue.

Results: F-VAS had a rising trend. The maximum reported fatigue occurred during 90 - 100 minutes of driving and equaled to 7.71 that was a sate between strong and moderate fatigue. The least level of fatigue was reported in the initial 10 minutes of driving (3.57). The study revealed a significant correlation between absolute Beta power and self-assessment of mental fatigue $(r=0.664$, $\mathrm{P}=0.018$ ).

Conclusions: F-VAS rating had a rising trend, and fatigue level increased as the time on task of driving increased. In the present study, the relatively steep upward slopes in the beta activity were observed with increasing fatigue. In contrast to the findings of the present study, Lal and Craig (2002) found significant increases in the alpha and delta activities during fatigue. It seems, contrary to the old belief, that alpha activity was the most reliable indicator of fatigue. Therefore, changes in the beta activity can be a good index of fatigue.

Keywords: Mental Fatigue, EEG, Bus Driver

\section{-Cognitive Features Hierarchical Analysis of 6 Dynamic Symbols in Designing a Technology of Warning Lane Departure to Other Drivers}

\section{Mostafa Pouyakian 1, Hadi Maddahi 2,3,", Farhad Tabatabai Ghomshe ${ }^{3,4}$, Leila Piri ${ }^{2}$}

\footnotetext{
${ }^{1}$ Department of Occupational Health Engineering, School of Public Health, Shahid Beheshti University of Medical Sciences, Tehran, IR Iran

2 Ergonomics Laboratory, Department of Occupational Health Engineering, Health Faculty, Tabriz University of Medical Sciences, Tabriz, IR Iran

${ }^{3}$ Department of Ergonomics, University of Social Welfare \& Rehabilitation Sciences, Tehran, IR Iran

${ }^{4}$ Pediatric Neuro-rehabilitation Research Center, University of Social Welfare \& Reha-
} bilitation Sciences, Tehran, IR Iran

* Corresponding author: Hadi Maddahi, Ergonomics Laboratory, Department of Occupational Health Engineering, Health Faculty, Tabriz University of Medical Sciences, Tabriz, IR Iran. Tel: +98-4133357581 (Ext. 406), E-mail: maddahih@tbzmed.ac.ir

\section{Abstract}

Background: Inattention, distraction, and drowsiness are the most risky driving behaviors that cause lane departure, imposing a serious threat for other drivers. Thus, developing a new technology of lane departure warning system to warn other drivers and avoid crashes is of prime importance.

objectives: The present study aimed at comparing the cognitive features of 6 dynamic lane departure warning symbols and selecting the best one to be presented as a newly designed sym- 
bol to be used in an innovative lane departure warning system (LDWS) to alert other drivers.

Methods: A random sample size of 187 volunteer driving license applicants, aged 18 - 28 years $(M=20.58, S D=3.20)$ was selected among 3 geographical regions (north, center, and south) of Tehran. The participants compared 6 dynamic symbols based on simplicity, familiarity, concreteness, meaningfulness, and semantic closeness as cognitive criteria using Analytic Hierarchy Process (AHP) method.

Results: According to pairwise comparisons based on the AHP method, meaningfulness and semantic closeness received the highest weight indices, respectively, and were determined as the most important criteria to be considered in the design process of warning symbols. Subsequently, symbols where the car element was used, received higher weighted average scores than the other symbols.

Conclusion: The most considerable result of the current study, which distinguished it from that of previous studies in the field, was using AHP method to estimate the weights of each cognitive feature as the criteria of evaluating symbols. The result of prioritizing symbols through AHP method was converged with the result of the same study using Likert scale. Because of using the dynamic mode in designing the symbols, it was expected that the best-introduced symbol in the current study could bring about a better comprehension in drivers about lane departure compared to the similar symbol presented by ISO.

Keywords: LDWS, Dynamic Symbol, Cognitive Features, AHP

\section{-Movement Variability and Coordination in Healthy and NLBP Participants During Repetitive Trunk Bending: The Effect of Control Parameters Such as Speed, Load, and Motion Symmetry}

\author{
Hamid Reza Mokhtarinia 1,", Sedighe Kahrizi ${ }^{2}$, \\ Mohammad Ali Sanjari ${ }^{3}$, Mohamad Parnianpour ${ }^{4}$ \\ ${ }^{1}$ Department of Ergonomics, University of Social Welfare and Rehabilitation Sciences, \\ Tehran, Iran \\ 2 Department of Physiotherapy, Tarbiat Modares University, Tehran, IR Iran \\ ${ }^{3}$ Biomechanics Lab, Rehabilitation Research Center, Faculty of Rehabilitation, Depart- \\ ment of Rehabilitation Basic Sciences, Iran University of Medical Sciences, Tehran, IR \\ Iran \\ ${ }^{4}$ Department of Mechanical Engineering, Sharif University of Technology, Tehran, IR \\ Iran \\ *Corresponding author: Hamid Reza Mokhtarinia, Department of Ergonomics, Uni- \\ versity of Social Welfare and Rehabilitation Sciences, Tehran, IR Iran. Tel/Fax: +98 \\ 2122180119, E-mail: hrmokhtarinia@yahoo.com
}

\section{Abstract}

Background: To distinguish the motor behaviors, the coordination between entire limbs and body segments should be measured. Stable coordinated movements are produced by interaction between adjacent joints. Different joints are involved in trunk bending motion and may be influenced by control parameters such as speed and external load.

Objectives: The present study aimed at quantifying the effects of symmetry, speed, and load parameters on coordination and pattern stability of trunk flexion-extension and lower limb movement using dynamical systems approach. Moreover, the effect of nonspecific chronic low back pain (NCLBP) on dynamic interactions and variability features of coordinative structures were assessed.

Methods: Twenty-four healthy volunteers and 24 low back pain patients participated in the present study. Kinematic data were collected during repeated trunk bending motion in different conditions of symmetry, speed, and loading. Time-normalized and filtered sagittal angular data were used to calculate the continuous relative phase for each data point. Mean absolute relative phase (MARP) and deviation phase (DP) were derived to quantify the coordination and pattern variability of lumbopelvis, pelvis-hip, and hip-ankle segments.

Results: Mixed model ANOVA revealed more synchronous coordination and more stable patterns in NCLBP than in healthy controls. Movements in asymmetric conditions caused less in-phase and more variable coordination patterns. Coordination pattern was also more variable in low speed conditions. Speed had a significant effect on coordination between the ankle-hip segments. In this study, external load had no effect on the coordination and pattern stability of the segments.

Conclusions: Control task parameters may affect the coordination and pattern stability of trunk bending. Therefore, they should be considered during the ergonomic assessment of this functional task.

Keywords: Coordination, Pattern Stability, Low Back Pain, Trunk Bending, Relative

\section{-Cultural Ergonomics and Its Application in Creating Inclusive Warnings}

\section{Mohammad Hossein Kaveh 1, \\ ${ }^{1}$ Associate Professor, Research Center for Health Sciences, Institute of Health, Shiraz University of Medical Sciences, Shiraz, IR Iran \\ * Corresponding author: Mohammad Hossein Kaveh, Associate Professor, Research Cen- ter for Health Sciences, Institute of Health, Shiraz University of Medical Sciences, Shi- raz, IR Iran. E-mail: kaveh@sums.ac.ir}

\section{Abstract}

Background: Historical development of human studies shows major paradigm shifts from biomedical to bio-psycho-socio-spiritual paradigms in the field of health. These shifts can be linked to the broader shifts of the paradigm in science and epistemology from positivism to naturalism, and from single-stranded, discipline-based approaches to interprofessional approaches. Ergonomics has traditionally addressed the physical aspects of the work and its relationship with man. It evolved from studying the interactions between humans and their surrounding work environment. Nevertheless, studying other aspects of human existence including cognition and emotions, as well as sociocultural environment, and the interactions between them has created a new realm of knowledge known as cultural ergonomics. Cultural ergonomics, with the adoption of an interprofessional approach, seeks to identify and understand the impact of cultural factors on human performance and interactions between people in a working environment, and applying the knowledge gained in designing work-related systems and products. Interdisciplinary studies in cultural ergonomics in different fields including designing products, services, and systems, advertising, transethnic and international education systems, and improv- 
ing health and safety in the workplace clearly reveal the growing need for this branch of knowledge. Cultural ergonomics provides important lessons for designing risk communications, and understanding how people interact with warnings. The latter will be discussed briefly in this paper.

objectives: This paper aimed at shortly introducing cultural ergonomics, its brief history, and applications in creating inclusive warnings and risk communications.

Conclusion: Cultural ergonomics as a new field of knowledge has important messages not only for designing systems and products but also for academic programs including interprofessional teaching and research.

Keywords: Cultural Ergonomics, Risk Communication, Health

\section{-The Impact of Ergonomic Interventions on the General Health Conditions of Employees of Iran Khodro Company (IKCO)}

\author{
Mahnaz Mohammadi ${ }^{1,}$, , Asghar Nouran ${ }^{2}$ \\ ${ }^{1}$ MSc of Psychology \\ ${ }^{2}$ Master of HSE
}

* Corresponding author: Mahnaz Mohammadi, MSc of Psychology, Kilometer 14 Kara Road, Tehran, IR Iran. Tel: +98-2148212890; +98-9357505628, Fax: +98-2148224201, Email:M.Mohammadi226@gmail.com

\begin{abstract}
Background: Common occupational health problems in industrial settings such as improper workplace design, lack of fit between workers' capability and job requirements, and improper design of human-machine systems may lead to an increase in occupational accidents and injuries, productivity deterioration, and health threatening circumstances. The goal of ergonomics is to design tools and workplaces in accordance with the mental and physical characteristics of the workers to promote wellbeing and productivity of the employees.

Objectives: The present study aimed at examining the effects of ergonomic interventions on the general health conditions of the employees of Iran Khodro Company (IKCO).

Methods: The study population consisted of 2 groups of employees working in the production units of IKCO. Workers from workstations with ergonomic interventions formed the first group (n $=35$ ), and those workers from workstations without any corrective interventions formed the second group $(n=35)$. Data were collected using the general health questionnaire (GHQ-28) with 4 subscales including somatic symptoms, anxiety and sleep disorder, social function, and depression. The general health conditions of the 2 groups were compared by statistical analysis. Result: According to the statistical analysis, the mean scores obtained in all 4 subscales and the total score of the GHQ for the first group were significantly lower than those of the second group $(\mathrm{P}<0.05)$. This finding indicated that the general health conditions of the employees in the group with ergonomic intervention were better compared to those of the second group, emphasizing the effectiveness of ergonomic corrective measures on improving the mental health status of the workers.

Conclusions: Corrective actions and ergonomic interventions had positive impacts on the general health status of IKCO employees.
\end{abstract}

Keywords: Ergonomics, Interventions, General Health
-The Relationship Between Job Stress and Smoking Among the Employees of a Petrochemical Industry Based on the Job Demands and Control Model

\author{
Siamak Poorabdian "1, Ehsanollah Habibi ', \\ Mahnaz Shakerian 2," \\ ${ }^{1}$ Department of Occupational Health, School of Hygiene, Isfahan University of Medi- \\ cal Sciences, Isfahan, IR Iran \\ 2 Occupational Health Department, School of Health, Shiraz University of Medical Sci-
} ences, Shiraz, IR Iran

* Corresponding author: Mahnaz Shakerian, Occupational Health Department, Schoo of Health, Shiraz University of Medical Sciences, P. O. Box: 71645-111, Shiraz, IR Iran. Tel: +98-7117251020, Fax: +98-7117260225, E-mail: shakerianm@sums.ac.ir

\begin{abstract}
Background: Smoking is obviously one of the adverse effects of job stress, which is followed by different health impacts on the workforce. Occupational stress should be essentially investigated by functional models; one of which is job demands and control model.

Objectives: The present study aimed at investigating the relationship between stress at work and smoking as one of the most important behavioral consequences of job stress.

Methods: This was a descriptive analytical study on a population of 500 employees working in a petrochemical company. The participants responded to job control, job demands and job stress questionnaires. The health records of the workers were used to determine the smoking status. Chi-square test was used to examine the association between smoking and job stress.

Results: Those workers with a relatively high stress showed a higher tendency to smoke (40.8\%). The number of people who tended to smoke and had a higher stress level was relatively large in operation (12.8\%). According to the chi-square test $(\chi=$ 64.453) $($ P value $=0.01)$, the personnel with relatively high stress showed a significant association with tobacco consumption. Conclusion: With an increase in the level of reported job stress, the tendency to smoke may also increase. The use of tobacco including cigarettes can be one of the stress-induced behavioral consequences in the workplace.
\end{abstract}

Keywords: Job Demands and Control Model, Job Stress, Smoking

\section{-Identifying Factors Affecting the Return-to-Work of National Iranian Oil Company Administrative Staff with a History of Low Back Pain in Kharg Island}

Adel Mazloumi 1,", Maryam Khodadadi ${ }^{1}$, Maryam Nourollahi Darabad ${ }^{1}$

${ }^{1}$ Occupational Health Engineering, School of Public Health, Tehran University of Medical Sciences, Tehran, IR Iran

* Corresponding author: Adel Mazloumi, Occupational Health Engineering, Schoo of Public Health, Tehran University of Medical Sciences, Tehran, IR Iran. Tel: +982188951390, Fax:+98-2188954781, E-mail: amazlomi@tums.ac.ir

\section{Abstract}

Background: Musculoskeletal disorders are the major causes of employees' work-related problems and half of all workplace absences. 
Objectives: The present study aimed at identifying the factors affecting the return-to-work of those administrative staff with a history of low back pain.

Methods: In this cross-sectional study, cluster sampling was used to select 303 administrative employees at Iranian Oil Terminals Company in Kharg Island as the sample. A questionnaire consisting of 4 sections was designed. The first 2 sections covered questions on demographic and occupational characteristics. The third section dealt with type, duration, and treatment of low back pain, the duration and method of recovery, and the time of recommencement of the work. The fourth section examined the return-to-work. Data were analyzed using SPSS software. Results: Eighty-five participants (28.1\%) suffered from low back pain. The evaluation of demographic, occupational, and organizational characteristics revealed that return-to-work was significantly related to age, physical activity, individual intervention, workplace intervention, and organizational support. According to the data collected from the respondents, from among the factors affecting the return-to-work, lifestyle change had the highest percentage frequency.

Conclusions: Less physical activity at work and younger age were among the factors associated with an increase in the likelihood of a return-to-work. Employees receiving organizational support had also an increased chance of a return to work. Thus, individual interventions such as lifestyle change, and workplace interventions including changes in workstation and work postures, and organizational support can have significant impacts on employees' return-to-work.

Keywords: Back Pain, Return to Work, Absenteeism, Administrative Staff

\section{Investigating Mental Workload in Air Traffic Control Using Electroencephalography (EEG) Signals}

Adel Mazloumi ${ }^{1}$, Marzieh Izadi Laybidi ${ }^{1,}$, Jebraeil Nasl Saraji ${ }^{1}$, Faramarz Gharagozlou ${ }^{2}$, Amir Homayoun Jafari ${ }^{3}$, Zahra Shirzhiyan ${ }^{3}$, Kamal Azam $^{4}$

${ }^{1}$ Department of Occupational Health Engineering, Tehran University of Medical Sciences, Tehran, IR Iran

${ }^{2}$ Department of Occupational Health Engineering, Kermanshah University of Medica Sciences, Kermanshah, IR Iran

${ }^{3}$ Department of Medical Physics and Biomedical Engineering, Tehran University of Med ical Sciences, Research Center for Biomedical Technologies and Robotics, Tehran, IR Iran

${ }^{4}$ Department of Epidemiology and Biostatistics, Tehran University of Medical Sciences, Tehran, IR Iran

*Corresponding author: Marzieh Izadi Laybidi, Department of Occupational Health Engineering, Tehran University of Medical Sciences, Tehran, IR Iran. Tel: +98-9106752748, E-mail: marziehizadi94@yahoo.com

\section{Abstract}

Background: Air traffic control is an incredibly complicated process that involves multiple human-machine interactions in which human mental workload plays a crucial role. Electroencephalography (EEG) indexes are considered as new indicators in the field of mental workload assessment.

Objectives: The present study aimed at investigating the mental workload in air traffic control using EEG signals.

Methods: Fourteen air traffic controllers participated in this study. Controllers carried out 2 scenarios including low and high workload based on task load factors in the air traffic control simulator.
Participants represented subjective mental workload assessment using the NASA task load index (TLX) questionnaire after the operation of each scenario. In addition, EEG signals were recorded continuously during the air traffic control tasks. Then, absolute theta power was extracted from the participants' EEG using Fast Fourier Transform (FFT) by the MATLAB software and was then compared with each other in terms of high and low workload.

Results: The results revealed that the controllers experienced a larger mental workload during the high workload scenario than the low workload scenario. In addition, a significant relationship was observed in absolute theta power during the low and high workload in all regions of the brain. Moreover, absolute theta power enhanced primarily at the frontal and central regions in the high workload conditions $(\mathrm{P}<0.05)$.

Conclusions: Absolute theta power provides a good index to assess the mental workload at different levels of air traffic control tasks. Therefore, it can be used as a measure to design humanmachine complex systems.

Keywords: Mental Workload, EEG, Air Traffic Control

\section{-An Ergonomic Study of Seat Headrest Effect on Neck Injury in Rear Crash}

\author{
Masoud Afrousheh ${ }^{1,}$, , Abdolkarim Rahmanian ${ }^{2}$, \\ Javad Marzbanrad ${ }^{3}$ \\ ${ }^{1}$ Ph.D. Candidate, School of Automotive Engineering, Iran University of Science and \\ Technology, Tehran, IR Iran \\ ${ }^{2}$ Associate Professor, Department of Neurosurgery, Shiraz University of Medical Sci- \\ ences, Shiraz, IR Iran \\ ${ }^{3}$ Associate Professor, School of Automotive Engineering, Iran University of Science \\ and Technology, Tehran, IR Iran
}

* Corresponding author: Masoud Afrousheh, Ph.D. Candidate, School of Automotive Engineering, Iran University of Science and Technology, Narmak, P. O. Box:1684613114, Tehran, IR Iran. Tel: +98-9014012002, Fax: +98-2177240364, E-mail: Afrousheh@aol.com

\section{Abstract}

Background: The seat plan of a vehicle is very important for drivers' safety. Many ergonomic researches have been conducted in this field since three decades ago. Lack of appropriate tools for ergonomic design and inattention to the different anthropometric characteristics of the drivers may cause serious injuries in car accidents.

Objectives: The present study aimed at investigating the effect of headrest of the drivers' seat on neck injuries in rear crash of car accidents.

Methods: To understand the injury mechanism, we investigated two cases of rear-end car accidents on the straight section of a highway. We then analyzed the front driver's neck injury. The PCCrash software was used to simulate a crash scenario. MADYMO software was applied to simulate the injuries of the occupants. Result: The headrest was modified in various ways to test the influence of different headrest properties on the head-neck motion during the simulated low-velocity rear-impacts. The results revealed that it might be possible to virtually eliminate the neck extension motion during the rear-impact by modifying the properties of the headrest.

Conclusions: The results of the present study revealed that a headrest position that is higher and closer to the driver's head might lead to a reduced risk of cervical spine injury. This position could significantly decrease the driver's neck tiredness while driving and lower the injury risk in the real world vehicle accidents.

Keywords: Ergonomics, Headrest, Neck Injury, Vehicle Crash 


\section{-Human Errors Assessment in the Control Room of Drilling Rig at MAPNA Company Using SHERPA Method}

\author{
Ali Karimi Pashaki ${ }^{1}$, Masoud Motalebi Kashani ${ }^{2,}$, \\ Mahnaz Nasrabadi ${ }^{1}$ \\ ${ }^{1}$ Department of Environmental Sciences, Azad University, Zahedan, IR Iran \\ ${ }^{2}$ Department of Occupational Health, Kashan University of Medical Sciences, Kashan, \\ IR Iran \\ * Corresponding author: Masoud Motalebi Kashani, Department of Occupational \\ Health, Kashan University of Medical Sciences, Kashan, IR Iran. Tel: +98-3155540111, \\ E-mail:motallebi_m@kaums.ac.ir
}

\begin{abstract}
Background: Human error is the main cause of accidents in industrial settings that can lead to major problems, ranging from minor accidents to destruction of systems. The drilling process, as the most important operation in the oil and gas industries, is no exception to this rule and can be affected by human error. Objectives: This study aimed at predicting and assessing human errors in control room operators of the drilling rig using SHERPA (systematic human error reduction prediction approach) method. Methods: This was a descriptive case study, and the required data were collected through direct observations, interviews, and review of the instructions and records. Occupational tasks were analyzed using the Hierarchical Task Analysis (HTA) technique. Human errors were identified in 5 domains: Functional, retrieval, checking, communication, and selection using SHERPA method. Then, qualitative risk analysis was conducted, and control solutions were presented.

Results: The total number of identified human errors was 100 cases; out of which, functional, retrieval, checking, communication, and selection errors accounted for $47 \%, 11 \%, 24 \%$, and $18 \%$ of the total errors, respectively. Risk levels, before corrective actions, included unacceptable level (40\%), acceptable level but requiring revision (32\%), and unfavorable level (28\%). After taking the proposed corrective action, the frequency of risk levels in all the cases was in an acceptable level, but required revision. Conclusions: Based on the findings of the present study, SHERPA is an appropriate method to detect human errors in the control room operators of the drilling rig and other sectors depending on the oil industry. This technique may be used to detect and reduce human errors through taking corrective actions and reducing accidents in such industries.
\end{abstract}

Keywords: Human Error, Drilling Rig, Risk Assessment, SHERPA Technique

\section{-Ergonomic Intervention Based on the Results of MAC and ART Evaluation Methods at Nestle Iran Company}

\author{
Mehran Ghalenoei ${ }^{1}$, Alireza Jalali ${ }^{2 *}$ \\ ${ }^{1} \mathrm{PhD}$ Student, Tarbiat Modares University, Tehran, IR Iran \\ ${ }^{2}$ Ms Student, School of HSE, Energy Facility Saveh, HSE Expert Nestle Company, Qazvin, \\ IR Iran \\ ${ }^{*}$ Corresponding author: Alireza Jalali, Ms Student, School of HSE, Energy Facility Saveh, \\ HSE Expert Nestle Company, The End of University Avenue, Moalem Boulevard, Ghoz- \\ zat Cui, L. 10, No. 8, Qazvin, IR Iran. Tel: +98-9123159865, E-mail: Jalali.hse@gmail.com
}

\begin{abstract}
Background: Uninterrupted growth of the industries and competition between the organizations towards faster production increase manual material handling activities. Additionally, with the mechanization of the industry and innovation in the production of modern machinery, doing repeated tasks by the operator in interaction with machines has had an increasing trend. Objectives: The present study aimed at implementing some ergonomic interventions in the Nestle Company to improve working conditions.
\end{abstract}

Methods: Sixty-three workstations (including 360 individuals) in production, packing, and storage workstations were evaluated using manual assessment chart (MAC) and assessment repetitive task (ART) methods. First, multiple videos and pictures from different postures were prepared (315 photos) and analyzed using the above-mentioned methods. The workstations were prioritized based on the evaluation scores. Then, ergonomic interventions were tailored for each workstation. After a 6-month period, the working conditions were re-evaluated.

Results: Among the 63 evaluated workstations, one station was in the red zone (danger), 32 in the yellow zone (warning), and 30 in the green zone (safe). To reduce the ergonomic risks and improve working conditions, 680 corrective actions were defined. To date, 198 actions were implemented (29\%), which have resulted in reduced evaluation scores of the workstations. After the 6-month period, the re-evaluation has proved the effectiveness of the interventional corrective measures.

Conclusion: Performing ergonomic assessments by MAC and ART methods resulted in complete coverage of activities that could have led to musculoskeletal disorders. Ergonomic interventions implemented in the company based on the identified priorities led to a decrease in the risk score of the activities and improvement in workplace conditions.

Keywords: Ergonomic Intervention, MAC, ART, Evaluation

\section{-Ergonomically Adjustable Laptop Desk Designed Based on Anthropometric Data of Students of Mazandaran University of Medical Sciences Aged 20 to 30 Years}

\author{
Mohammad Amin Mououdi ${ }^{1}$, Royan Shahpuri ${ }^{2, *}$, \\ Ismail Shukrolahi $^{2}$ \\ ${ }^{1}$ Mazandaran University of Medical Sciences, Faculty of Health, Sari, IR Iran, @ Student \\ Research Committe \\ 2 Occupational of Health Student, Mazandaran University of Medical Sciences, Sari, IR \\ Iran, @ Student Research Committee \\ * Corresponding author: Royan Shahpuri, Occupational of Health Student, Mazanda- \\ ran University of Medical Sciences, Sari, IR Iran, @ Student Research Committee. Tel: \\ +98-1154280301; +98-9011565138, E-mail: er.shahpouri@gmail.com
}

\begin{abstract}
Background: Musculoskeletal disorders in different body parts such as wrists, elbows, neck, back, and shoulders are common among many computer and laptop users.

objectives: The present study aimed at designing an appropriate laptop desk based on anthropometric dimensions to reduce musculoskeletal loads on the users.

Method: In this cross sectional study, the anthropometric dimensions of 108 individuals including 61 male and 47 female students
\end{abstract}


of Mazandaran University of Medical Sciences were measured to be used for laptop desk design. The dimensions measured were as follow: knee height sitting on a chair, eyes-elbows distance, crosslegged posture kneeling length, cross-legged posture kneeling height, thigh thickness, elbow rest height sitting, shoulder-fingertip length, abdominal depth, hip breath, and elbow-fingertip length. The measurements were performed using caliper and meters. Based on the anthropometric data and considering the ergonomics principles, a laptop desk was designed and fabricated.

Results: The mean age of the participants was $23 \pm 3.135$ years. The percentile values of 1, 5, 50, 95, and 99 were calculated for all dimensions for both sexes. Then, using the laptop golden number of 1.618, the width and the length of the desk were calculated. The desk height adjustable range was determined based on the screen height and the user viewing distance.

Conclusions: Using the newly designed desk may improve the users' working postures and reduce musculoskeletal discomfort while working with laptops.

Keywords: Ergonomics, Laptop, Desk, Design, Anthropometry

\section{-Surveying the Relationship Between Organizational Support and Physical Environment Conditions with Burnout of Employees in Yazd Social Security Organization Hospital}

\author{
Naser Sadra Abargouei ${ }^{1,},{ }^{,}$Hamirdreza Jafarpour ${ }^{2}$ \\ ${ }^{1}$ University of Applied Science and Technology, Yazd, IR Iran \\ 2 Student of Public Administration, Azad University, Yazd, IR Iran \\ * Corresponding author: Naser Sadra Abargouei, University of Applied Science and Tech- \\ nology, Daneshjoo St., Yazd, IR Iran. Tel: +98-3538264880, Fax: +98-3538274173, E-mail: \\ Sadra@uast.ac.ir
}

\begin{abstract}
Background: A vast number of employees are suffering from burnout in different countries. It is clear that preventing of burnout plays an important role in promoting mental health and improving the quality of services and working life. Studies have shown that macro ergonomics researches and interventions improve working conditions and reduce work stress among the employees.

Objectives: The present study aimed at surveying the relationship between organizational support and physical environment conditions with the burnout of employees in Yazd social security organization hospital.

Methods: Two hundred sixteen randomly selected employees of Yazd social security organization hospital participated in this crosssectional study. The data were collected using a questionnaire.

Results: The results revealed that burnout and perceived organizational support were in intermediate and low level, respectively. Moreover, a significant negative relationship was found between burnout and organizational support and physical environment conditions variables. Additionally, gender, age, and work experience were found to be associated to burnout.

Conclusion: Based on the study results, one may infer that in creasing organizational support and improving physical environment conditions in the workplace could result in reducing burnout prevalence and severity among the employees.
\end{abstract}

Keywords: Macro Ergonomics, Burnout, Organizational Support, Physical Environmental Conditions

\section{-The Relationship Between Lighting and Visual Eye Fatigue and Sleep Quality in Video Display Terminal (VDT) Users}

\author{
Niloofar Ziayi ${ }^{1}$, Zahra Sharifian ${ }^{1}$, Habibollah \\ Dehghan ${ }^{2, *}$
}

${ }^{1}$ MSc Student, Department of Occupational Health, School of Health, Member of Student Research Committee, Isfahan University of Medical Sciences, Isfahan, IR Iran

2 Assistant Professor, Faculty Member, Department of Occupational Health, School of Health, University of Medical Sciences, Isfahan, IR Iran

* Corresponding author: Habibollah Dehghan, Assistant Professor, Faculty Member, Department of Occupational Health, School of Health, University of Medical Sciences, Isfahan, IR Iran. Tel: +98-3137923264, E-mail: ha_dehghan@hlth.mui.ac.ir

\section{Abstract}

Background: The most complaints of VDT users are pain and pressure around the eyes, blurred vision, eye fatigue, sleep disorders, poor quality of sleep, and inappropriate lighting, which may cause error and reduce precision.

objectives: The present study aimed at investigating the relationship between lighting and sleep quality and eye fatigue in VDT users.

Methods: This descriptive cross-sectional study was conducted on 191 VDT users in February 2016. Pittsburg sleep quality and eyes fatigue questionnaires were used. Lux meter device was used to measure lighting.

Results: The average of eye fatigue score before and after work was $1.03 \pm 0.72$, and $2.66 \pm 2$, respectively. Moreover, the increase of fatigue was measured to be $1.93 \pm 1.67$. The mean intensity of lighting was 345.34 \pm 274.3 . Lux and Sleep Quality Index score was $6.29 \pm 2.67$. No significant correlation was found between lighting and difference of visual fatigue $(\mathrm{P}=0.55)$. The relationship was significant between eye fatigue and sleep quality score ( $\mathrm{r}$ $=0.33, \mathrm{P}<0.001)$. However, no significant relationship was obtained between lighting and sleep quality $(\mathrm{P}=0.57)$. The results of regression analysis revealed that sleep quality and visual condition influenced fatigue. Between these two parameters, sleep quality was even more significant.

Conclusion: The results revealed a negative relationship between eye fatigue and sleep quality. Therefore, to improve sleep quality and reduce eye complaints, it is highly important to rest during the work.

Keywords: Lighting, Eye Fatigue, Sleep Quality

\section{Measuring Anaerobic Power and Speed of Muscle Contraction: Criterion for Selecting Medical Emergencies Students}

\author{
Payam Heydari ${ }^{1}$, Sakineh Varmazyar ${ }^{2, *}$ \\ ${ }^{1}$ MSc Student, Department of Occupational Health Engineering, Qazvin University of \\ Medical Sciences, Qazvin, IR Iran \\ ${ }^{2}$ Assistant Professor, Department of Occupational Health Engineering, Qazvin Univer- \\ sity of Medical Sciences, Qazvin, IR Iran \\ * Corresponding author: Sakineh Varmazyar, Assistant Professor, Department of Occu- \\ pational Health Engineering, Qazvin University of Medical Sciences, Qazvin, IR Iran. \\ Tel: +98-2833359501, Fax: +98-2833359501, E-mail: svarmazyar@qums.ac.ir
}

\section{Abstract}

Background: Due to the difficulty in emergency medicine jobs, employees must have high physical fitness. 
Objectives: The present study aimed at measuring anaerobic power and speed of muscle contraction in medical emergency students and using the results as parameters to select students in this field.

Methods: This analytical-descriptive and cross-sectional study was conducted among all 47 students of Qazvin emergency medicine. Sargent jump test was used to measure the ability of the leg muscles (known as vertical jump test). To measure the speed of muscle contraction, 45 meters or 50 yards running test was conducted.

Results: According to Sargent jump test, 59.9\% of the students aged 16 - 19 years, 39.3\% in the same age range, and those students older than 20 years were in poor or very poor category in the ability of the leg muscles. All participants had high levels of speed (measured by run 45 meters). The results of independent t-tests and ANOVA revealed that height, weight, and body mass index (BMI) had a significant relationship $(\mathrm{P}<0.001)$ with the mean anaerobic power of Sargent jump and 45-meters running test.

Conclusions: The results of the present study revealed that demographic variables including weight, height, and BMI were the factors influencing the mean anaerobic power and speed of muscle contraction. The students were in normal condition in terms of physical fitness and speed. Individuals with poor body composition or muscle power are not suitable candidates for medical emergency.

Keywords: Anaerobic, Power, Muscle, Contraction, Emergency Medicine

\section{-A Survey on Ergonomics Research Trend in Iran Based on Papers Published in Scientific Persian Language Journals During 2013 to 2015}

\section{Shirazeh Arghami ${ }^{1}$, Mostafa Pouyakian ${ }^{2, *}$, Niloofar Mahdizadeh ${ }^{1}$, Shabnam Mohammadgholiha ${ }^{1, *}$}

${ }^{1}$ Department of Occupational Health Engineering, Health Faculty, Zanjan University of Medical Sciences, Zanjan, IR Iran

2 Department of Occupational Health Engineering, School of Public Health, Shahid Beheshti University of Medical Sciences, Tehran, IR Iran

* Corresponding author: Mostafa Pouyakian, Department of Occupational Health Engineering, School of Public Health, Shahid Beheshti University of Medical Sciences, Tehran, IR Iran. Tel: +98-2122432040 (Ext. 237), E-mail: pouyakian@sbmu.ac.ir, Shabnam Mohammadgholiha, Department of Occupational Health Engineering, Health Faculty, Zanjan University of Medical Sciences, Zanjan, IR Iran. Tel: +98-24333781301, E-mail: shabnam.mgh73@yahoo.com

\footnotetext{
Abstract

Background: The increasing amount of scientific data in the recent decades has aroused the creation and use of scientometrics indices. Determining the research trend in any scientific filed will help the researchers to choose better topics. It also enables the journal editors to update their strategic plans to call and publish newer studies.

Objectives: This meso-level scientometrics study aimed at providing an updated classification of the main areas in the field of ergonomics in Iran. In addition, the direction of ergonomics researches was investigated in a new classification based on the papers published in scientific Persian language journals during 2013 to 2015

Methods: The main areas of ergonomics were determined using
}

a 3 round classic Delphi method. All Persian language electronic journals that have published at least one paper related to ergonomics during 2013 to 2015 were identified. Papers on ergonomics were downloaded and their metadata were extracted. Papers were assigned to the categories of new classification of ergonomics based on the content analysis of the title and keywords. Results: Seven main areas of ergonomics were identified including physical ergonomics, environmental ergonomics, cognitive ergonomics, macro-ergonomics, system ergonomics, ultra-ergonomics (eco-ergonomics, sociocultural ergonomics and ergonomics in developing countries), and ergonomics of design, optimization, and usability. A total of 63 scientific journals and 313 ergonomics-related papers were identified. During 2013 to 2015, physical ergonomics and cognitive ergonomics have gained the most attention from the researchers. Moreover, in this period, no papers were published on ultra-ergonomics category. Furthermore, $84 \%$ of the affiliations were related to the occupational health specialists.

Conclusions: The main direction of ergonomics researches is toward the physical and cognitive ergonomics, and an added knowledge and experience of research is available in these areas in Iran. Neglected areas of ergonomics researches in Iran should gain more attention from the researchers. Creating multidisciplinary research teams and improving intra-organizational corporations between universities can help achieve this goal. Results of this study can be used by Persian language scientific journal editors and researchers in the field of ergonomics.

Keywords: Ergonomics, Iran, Research, Scientometrics, Trend

\section{-The Effects of Light Color Temperature on Circadian Rhythm, Sleepiness, and Cognitive Functions of Night Shift Workers}

Reza Kazemi 1,", Rashid Haidarimoghadam ${ }^{2}$, Majid Motamedzadeh ${ }^{3}$, Rostam Golmohamadi ${ }^{3}$, Alireza Soltanian ${ }^{4}$, Mohamadreza Zoghipaydar ${ }^{5}$

${ }^{1}$ Assistant Professor, Ergonomics Department, Shiraz University of Medical Sciences, Shiraz, IR Iran

${ }^{2}$ Assistance Professor, Ergonomics Department, Hamedan University of Medical Sciences, Hamedan, IR Iran

3 Professor, Ergonomics Department, Hamedan University of Medical Sciences, Hamedan, IR Iran

${ }^{4}$ Associate Professor, Department of Biostatistics \& Epidemiology, Hamadan University of Medical Sciences, Hamedan, IR Iran

${ }^{5}$ Assistant Professor, Department of Psychology, Bu-Ali Sina University, Hamedan, IR Iran

* Corresponding author: Reza Kazemi, Assistant Professor, Ergonomics Department, Shiraz University of Medical Sciences, Shiraz, IR Iran. E-mail: reza_kazemi2007@yahoo. com

\begin{abstract}
Background: Night shift works are usually accompanied by reduced cognitive performance, sleepiness, and higher possibility for human error, and related incidents. It is, therefore, crucial to improve individuals' performance and alertness in sensitive places like industries' control rooms to improve efficiency and reduce the number of possible incidents. Previous research has indicated that blue light is a critical cue for entraining circadian rhythm.

Objectives: As a result, the present study aimed at investigating
\end{abstract}


whether blue-enriched white light illumination was a practical strategy to decrease melatonin and sleepiness and improve cognitive performance during the night shifts.

Methods: The present study, with its before-after interventional design, was conducted on 30 control room staff members of petrochemical industry. After baseline assessments under the existing lighting conditions, every participant was exposed to 2 new lighting conditions (namely, 17,000 Kand 6,500 K blue-enriched white light), each lasting for a week. Subsequently, assessments were conducted again. More specifically, melatonin assessment was conducted using salivary and Eliza technique. On the other hand, karolinska sleepiness scale (KSS) was used to assess the degree of sleepiness, while n-back cognitive test and continuous performance test were applied to measure the cognitive performance.

Results: The results revealed that compared to normal lighting conditions, participants' sleepiness and melatonin rhythm significantly declined when they were exposed to blue-enriched white light. Furthermore, the experimental condition had a significant effect on the reduction of working memory errors. It also decreased omission errors and the reaction time during the sustained attention task.

Conclusions: Using blue-enriched white light may be a proper ergonomic strategy for improving performance and alertness in sensitive environments like control rooms, especially during the night time.

Keywords: Night Work, Light's Color Temperatures, Cognitive Performance, Sleepiness, Melatonin

\section{nHousekeeping or Employment: From the Perspective of Musculoskeletal Pain}

\section{Roghaye Nouri ${ }^{1}$, Shirazeh Arghami ${ }^{1,}$, Kourosh Kamali $^{2}$}

${ }^{1}$ Occupational Health Engineering Department, Zanjan University of Medical Sciences, Zanjan, IR Iran

2 Epidemiologist, Zanjan University of Medical Sciences, Zanjan, IR Iran

* Corresponding author: Shirazeh Arghami, Occupational Health Engineering Department, Zanjan University of Medical Sciences, Zanjan, IR Iran. Tel: +98-2433773128, Fax +98-2433773154, E-mail: arghami@zums.ac.ir

\section{Abstract}

Background: There is a common belief among people that employment is a harmful factor for women's health. Yet, one can hardly find any scientific data to support this view. Therefore, this study aimed at comparing the risk of suffering from musculoskeletal pain between housewives and employed women. Materials and Methods: Four hundred housewives and $537 \mathrm{em}-$ ployees participated in this cross-sectional study. The data were collected using Nordic musculoskeletal disorders questionnaire, which focuses on 9 parts of the body. Demographic data were collected simultaneously. Written informed consent was obtained from all the participants. Statistical analysis including t-test, regression and odds ratio were performed, taking into account the significance statistical level of less than 0.05 .

Results: The results of the present study revealed that pain complaints about 4 parts of the body in lower limbs (lower back, hips/thighs, ankles, and feet) were higher in housewives (OR $>1$, $\mathrm{P}<0.05)$. However, the results could be adjusted by dichotomiza- tion of jobs into sedentary (with light force or repeated motion) and high demand (full dynamic and/or repeated motion based). Furthermore, it was found that pain complaints of lower limbs in participants with a sedentary job was less than the housewives, and in turn, the same complaints for housewives was less than the employed women with high demand tasks $(\mathrm{P}<0.05)$.

Conclusion: The findings of this study revealed that sedentary jobs with light force and little repeated motion have no harmful effect on this pain. However, high demand jobs may strongly increase the risk of musculoskeletal pain in women.

Keywords: Employment, Housewife, Musculoskeletal Disorders, Nordic Questionnaire

\section{-Ergonomics Modification to Prevent Musculoskeletal Injuries in the Personnel of Iran Khodro Warehouse}

\author{
Smaeil Poursmaeil ${ }^{1}$, Seyed Mohammad Jafari 2,, \\ Hamid Reza Barikbin ', Mohammad Kazem \\ Yadollahzadeh $^{1}$ \\ ${ }^{1}$ Car Production Planning, Iran Khodro, Tehran, IR Iran \\ ${ }^{2}$ Mechanical Engineering Department, Shahid Beheshti University, Teharn, IR Iran \\ * Corresponding author: Seyed Mohammad Jafari, Mechanical Engineering Depart- \\ ment, Shahid Beheshti University, Evin, P. O. Box: 19839-4716, Tehran, IR Iran. Tel: +98- \\ 2129903244, Fax: +98-2122431964, E-mail: M_Jafari@sbu.ac.ir
}

\section{Abstract}

Background: The physical and mental health of employees in the workplace is a main indicator of organizational productivity in the competitive market of industry. Medical reports have shown that most warehouse employees are experiencing back pain due to repeated movements and manual handling of pieces and raw materials.

Objectives: The present study aimed at identifying and evaluating the effects of ergonomic interventions in reducing the exposure of employees to risk factors of musculoskeletal injuries.

Methods: MAC method has been developed to identify highrisk workplaces from the viewpoint of manual handling activities and can be used to assess the risks posed by lifting, carrying, and team manual handling activities. Studies have found that MAC method can effectively identify the high-risk workplaces. In the present study, 14 warehouses containing 35,000 pieces were evaluated by MAC method in Iran Khodro Company. Four risk categories were introduced to separate all handling activities including low, medium, high, and very high-risk activities.

Results: The study findings revealed that the factors including weight of the pieces, lifting repetition rate, the horizontal distance of lifting, and lifting height, and postural constraints were the most effective factors in biomechanical stress. These factors were taken into account in ergonomics interventional programs in the workplace. To implement the corrective measures, we tried to change high and very high-risk activities to low and medium risk level activities. Thus, workers' training, arrangement of items in the stock based on their weights, designing a hydraulic table to reduce the manual handling of the pieces, and finally modifying the pallets of the items were considered as corrective measures to ergonomically improve the working conditions. As a result, musculoskeletal disorders decreased after implement- 
ing the ergonomics interventions in Iran Khodro stocks. This was confirmed by medical reports following the interventions.

Conclusion: The ergonomics interventions effectively reduced the risk level of musculoskeletal injuries in the warehouse unit of Iran Khodro Company.

Keywords: Ergonomics Intervention, MAC Method, Musculoskeletal Injuries

\section{-Designing a New Table Based on Iranian Anthropometric Data and Evaluating Its Effects on the Users Posture While Working with the Microscope}

\author{
Toktam Balande ${ }^{1}$, Zahra Zamanian ${ }^{2,}$, Mohsen \\ Razeghi ${ }^{3}$, Taymaz Shahnazar Nezhad Khales ${ }^{4}$ \\ ${ }^{1}$ Graduate Student, Department of Ergonomics, Faculty of Health, Shiraz University of \\ Medical Sciences, Shiraz, IR Iran \\ 2 Associate Professor, Department of Ergonomics, Shiraz University of Medical Sci- \\ ences, Shiraz, IR Iran \\ ${ }^{3}$ Associate Professor, Department of Ergonomics, Faculty of Rehabilitation Sciences, \\ Shiraz University of Medical Sciences, Shiraz, IR Iran \\ ${ }^{4}$ Msc, Institute of Mechanics, Shahid Bahonar College of Technology and Engineering, \\ Shiraz, IR Ira \\ * Corresponding author: Zahra Zamanian, Associate Professor, Department of Ergo- \\ nomics, Shiraz University of Medical Sciences, Shiraz, IR Iran.Tel: +98-9177168775; +98- \\ 9333024081, Fax:+987137260255, E-mail: zamanianz@sums.ac.ir
}

\begin{abstract}
Background: Microscope users are exposed to continuous static muscular work and increased risk of musculoskeletal disorders in the neck, shoulder, wrist, hand, fingers, and upper and lower back.

Objectives: This study aimed at designing and evaluating a new ergonomic table for working with a microscope based on Iranian anthropometrics to reduce musculoskeletal disorders and increase users comfort.

Methods: First, the new table was built based on design principles, the anthropometric data of Iranian users, and ergonomic principles. To evaluate and compare the new table (with adjustable eyepiece tilt and height, and adjustable table height and forearm support tilt) to a conventional table (non-adjustable), discomfort was measured using Body Map, and posture was evaluated using RULA (Rapid Upper Limb Assessment), and Ergo Intelligence software after and during a standard task with microscope, respectively. Each table was evaluated in 10 healthy microscope users. Data were analyzed using Kolmogorov-Smirnov and Wilcoxon test via SPSS version 20

Results: The results revealed that the designed ergonomic table could be used as a tool to make possible the near-perfect posture for users. The evaluation results showed that the mean scores for the postures of the head and neck, shoulder and arm, back, elbow and forearm, hand, and wrist in the conventional table were $3.7,3.04,3.3,2.64$, and 2.76 , respectively, which were more than the ergonomic table values. In other words, the conventional table was inappropriate. Analysis of the RULA results detected a statistically significant difference between the posture grand score and action level of the ergonomic table compared to the conventional table. The action level in the ergonomic table and the conventional table was 1 and 2 , respectively.
\end{abstract}

Conclusions: The results revealed that the use of the new table allowed the user to maintain the physiological state of organs. Moreover, the intervention (designed ergonomic table) had a significant impact and significantly decreased the discomfort in various parts of the body. Therefore, it seems that the designed ergonomic table can decrease disorders in these areas during a long-term work with microscopes.

Keywords: Microscope, Table Design, Anthropometric Data

\section{-Evaluation of Cardiorespiratory Fitness and Some Related Factors in the Fire-Fighting Personnel}

Touraj Khazraee ${ }^{1}$, Mohammad Fararouei ${ }^{2}$, Hadi Daneshmandi ${ }^{3}$, Farzane Mobasheri ${ }^{4}$, Zahra Zamanian ${ }^{5, *}$

${ }^{1}$ MSc Student, Shiraz University of Medical Sciences, Shiraz, IR Iran

${ }^{2}$ Association Professor, Shiraz University of Medical Sciences, Shiraz, IR Iran

${ }^{3}$ PhD Student, Research Center for Health Sciences, Institute of Health, Shiraz University of Medical Sciences, Shiraz, IR Iran

${ }^{4}$ Ms of Social Medicine, Fasa University of Medical Sciences, Fasa, IR Iran

${ }^{5}$ Associate Professor, Department of Ergonomics, Shiraz University of Medical Sciences, Shiraz, IR Iran

* Corresponding author: Zahra Zamanian, Associate Professor, Department of Ergonomics, Shiraz University of Medical Sciences, Shiraz, IR Iran. E-mail: zamanianz@sums. ac.ir

\section{Abstract}

Background: Firefighters and aid workers are considered the victims of heat stress in physiological activities. Moving and lifting heavy objects or saving people under stressful conditions are activities done by firefighters while wearing protective clothes and a compressed air breathing apparatus.

Objectives: This study aimed at investigating the cardiorespiratory system and its related factors among firefighters.

Methods: This study was conducted on 110 volunteer firefighters from various stations. An interview-administered questioner (Respiratory Disorders Questionnaire, Tuxworth-Shahnavaz step test, and pulmonary function test) was used to collect the demographic information. Data were analyzed using SPSS software, (Version 19)

Results: The mean age of the study participants was $32+6.2$ years. The means of forced vital capacity (FVC), forced expiratory volume in 1 second (FEV1), and FEV1/FVC were $92+9.4 \%, 87+9.2 \%$, and $80+6.1 \%$, respectively. The participants' mean VO2-max was $2.79+0.29 \mathrm{~L} / \mathrm{min}$, or $37.34+4.27 \mathrm{~mL} / \mathrm{kg}$ body weight per minute. The results revealed a direct association between weight and vital capacity (VC), FVC, and the peak expiratory flow (PEF). In addition, height was directly associated with vital capacity (VC), FVC, and VO2-max $(\mathrm{P}<0.05)$. However, a significant inverse association was found between height and FEV1/FVC $(\mathrm{r}=-0.2333, \mathrm{P}<$ 0.05 ). Height, weight, body mass index (BMI), and waist circumference were directly associated with VO2-max.

Conclusions: This study introduced excess fat tissues as a barrier to appropriate pulmonary function, and physical activity as a factor increasing VO2-max. Thus, proper exercising space and facilities should be provided for this group to increase their physical fitness.

Keywords: Cardiorespiratory Fitness, Fire-Fighting, VO2-Max 


\section{-The Effects of Shoe Insoles on Lower Leg Muscle Activity and Volume Changes During Prolonged Standing}

\author{
Zanyar Karimi ${ }^{1}$, Mahmood Reza Azghani ${ }^{2}$, \\ Teimour Allahyari ${ }^{3, *}$ \\ ${ }^{1}$ School of Health, Tehran University of Medical Sciences, Tehran, IR Iran \\ 2 Faculty of Mechanical Engineering, Sahand University of Technology, Tabriz, IR Iran \\ ${ }^{3}$ Department of Occupational Health, School of Health, Urmia University of Medical \\ Sciences, Urmia, IR Iran \\ ${ }^{*}$ Corresponding author: Teimour Allahyari, Department of Occupational Health, Schoo \\ of Health, Urmia University of Medical Sciences, Urmia, IR Iran. Tel: +98-4432752296, \\ Fax:+98-4432752296, E-mail: Allahyari@umsu.ac.ir
}

\begin{abstract}
Background: Application of shoe insoles as one of the ergonomic interventions is common for standing jobs with the aim of plantar pressure distribution and increased comfort. Considering the lack of sufficient attention to the role of insoles in altering the pattern of lower limb muscle activity, the present study aimed at investigating the effects of shoe insoles on lower leg muscle activity and volume changes during prolonged standing.

Methods: In this experimental study, 10 males with an average age of $25.3 \pm 1.49$ years were recruited to stand continuously with and without insoles for 2 hours in simulating laboratory settings. During standing, the lower leg volume changes bilaterally (through measuring calf environments before and after the standing), and the medial gastrocnemius and tibialis anterior muscle activity (using SEMG and in 15-minutes blocks) were monitored.

Results: Right medial gastrocnemius activity level $(\mathrm{P}=0.034)$, variation $(\mathrm{P}=0.048)$, and left medial gastrocnemius activity level $(P=0.038)$ reduced significantly during standing with insoles compared to non-insoles condition. Right and left tibialis anterior muscle activity pattern was similar in both shoe conditions. Lower leg volume changes were greater in standing with insoles for both legs, but the differences were significant only for the right leg $(\mathrm{P}=0.033)$ compared to noninsoles condition.

Conclusions: In the current study, reduced activity level and variation of the posterior calf muscles during prolonged standing with insoles could be related to maintenance of foot arches and increased stability by insoles, which could lead to reduced venous pumping ability and increased lower leg volume. Therefore, despite the short-term effects of the insoles, its application for prolonged standing should be handled with more caution. More studies are recommended to provide an appropriate solution to this problem of insoles.
\end{abstract}

Keywords: Shoe Insoles, Prolonged Standing, Muscle Activity, Leg Volume

\section{- Investigating Muscle Fatigue Trend in the Clutch Pedal Actuation of Four Automobile Models in Iran's Market}

\author{
Adel Mazloumi 1, Zeinab Kazemi 1,*, Hossein \\ ShirMohammadi ${ }^{1}$, Amir Homayoun Jafari ${ }^{2}$, Zahra \\ Shirjian ${ }^{2}$, Hossein AghaZade ${ }^{1}$ \\ 1 Department of Occupational Health Engineering, School of Public Health, Tehran \\ University of Medical Sciences, Tehran, IR Iran \\ 2 Department of Medical Physics and Biomedical Engineering, School of Medicine, \\ Tehran University of Medical Sciences, Tehran, IR Iran \\ * Corresponding author: Zeinab Kazemi, Department of Occupational Health Engineer- \\ ing, School of Public Health, Tehran University of Medical Sciences, Tehran, IR Iran. Tel: \\ +98-2188951390, E-mail:z-kazemi@razi.tums.ac.ir
}

\section{Abstract}

Background: Clutch pedal is one of the most important control parts of an automobile with a gear system. As a foot controller and due to its location and mechanism of action, the clutch pedal can decrease driver fatigue and provide comfort and safety of the vehicle in case of an improper design.

Objectives: This study aimed at determining the fatigue trend of lower extremity muscles in 4 automobile models in Iran's market including Samand, Paykan vanet, Tondar, and Peugeot 206.

Methods: The activity levels of rectus femoris, tibialis anterior, soleus, and gastrocnemius of 15 male volunteers were measured using surface electromyography (EMG) during clutch actuation according to a predetermined pattern. Moreover, to normalize data, EMG activity was recorded during maximum voluntary contraction (MVC) of each muscle.

Results: In the 4 automobile models, the highest activity level (mean root mean square: RMS) belonged to soleus and tibialis anterior. In addition, RMS was significantly different among the study automobiles in MVC, after and during clutch actuation. According to the post hoc test, RMS related to lateral gastrocnemius was statistically different between Tondar and Peugeot 206. Conclusions: The activity level of all selected muscles during the test showed a decreasing trend, which has been reported as a fatigue indicator in some previous studies. The level of muscle activity represents the higher activity of the soleus and tibialis anterior as the posterior and anterior compartments of the leg, comparing to other muscles. Ankle plantar flexion is the dominant movement while clutch actuation, by means of soleus is a relatively weak muscle. However, releasing the clutch is due to tibialis anterior contraction in the anterior compartment of the leg and is in the next priority of dynamic movements. Overall, the findings of the present study confirmed the need for optimization of the clutch mechanical components including force for clutch actuation, travel distance, and access, as well as design of driver cabin.

Keywords: Muscle Fatigue, Driver, Electromyography, Clutch Actuation 


\section{A}

Abbas Moradi

Abdolkarim Rahmanian

Adel Mazloumi

Adibeh Abdi

Ahmad Bazazan

Ali Ghanbari

Ali Karimi Pashaki

Ali Motie Nasrabadi

Ali Nahvi

Alireza Choobineh

Alireza Jalali

Alireza Mohammad Shirazi

Alireza Soltanian

Amir Homayoun Jafari

Aram Tirgar

Asghar Nouran

\section{$>\mathbf{E}$}

Ehsanollah Habibi

Ehsan Sinaei

Elham Salvarzi

\section{$>\mathrm{F}$}

Fahimeh Kamali

Faramarz Gharagozlou

Farhad Tabatabai Ghomshe

Farzane Mobasheri

\section{- $\mathbf{G}$}

Gebraeil Nasl Saraji

\section{- $\mathbf{H}$}

Habibollah Dehghan

Hadi Daneshmandi

Hadi Maddahi

Hamed Mozaffari

Hamid Reza Barikbin

Hamid Reza Mokhtarinia

Hamirdreza Jafarpour

Hossein AghaZade

Hossein ShirMohammadi

\section{$>$ I}

Ismail Shukrolahi

\section{$>$ J}

Javad Faradmal

Javad Marzbanrad

Jebraeil Nasl Saraji

\section{$>\mathrm{K}$}

Kamal Azam

Kourosh Kamali

\section{$>\mathbf{L}$}

Leila Piri

\section{M}

Mahmood Reza Azghani

Mahnaz Mohammadi

Mahnaz Nasrabadi

Mahnaz Shakerian

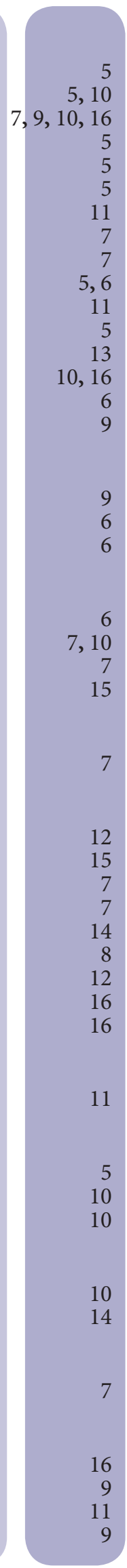

Majid Motamedzadeh

Maryam Khodadadi

Maryam Nikpour

Maryam Nourollahi Darabad

Marzieh Izadi Laybidi

Masoud Afrousheh

Masoud Motalebi Kashani

Mehdi Jahangiri

Mehran Ghalenoei

Mohamad Ghorbani

Mohamad Parnianpour

Mohamadreza Zoghipaydar

Mohammad Ali Sanjari

Mohammad Amin Mououdi

Mohammad Fararouei

Mohammad Hossein Kaveh

Mohammad Kazem Yadollahzadeh

Mohammadreza Ashouri

Mohsen Razeghi

Mojgan Firouzbakht

Mostafa Pouyakian

\section{$>\mathbf{N}$}

Nafiseh Feizollahi

Naser Sadra Abargouei

Niloofar Mahdizadeh

Niloofar Ziayi

$>\mathbf{P}$

Payam Heydari

Rashid Haidarimoghadam

Rashid Haydarimoghadam

Reza Kazemi

Reza Sadeghian

Roghaye Nouri

Rostam Golmohamadi

Royan Shahpuri

$$
\checkmark \mathrm{S}
$$

Sakineh Varmazyar

Sareh Keshavarzi

Sedighe Kahrizi

Seyed Mohammad Jafari

Shabnam Mohammadgholiha

Shirazeh Arghami

Siamak Poorabdian

Smaeil Poursmaeil

\section{$\mathbf{T}$}

Taymaz Shahnazar Nezhad Khales

Teimour Allahyari

Toktam Balande

Touraj Khazraee

\section{$>\mathbf{Z}$}

Zahra Sharifian

Zahra ShirJian

Zahra Shirzhiyan

Zahra Zamanian

Zanyar Karimi

Zeinab Kazemi

Zohreh Mombeini
5,13

9

9

10

11

6

11

5

8
13

8

15

14

7

5,15

6

7,13

5

12

13 